\title{
Thermal Dependence of Locomotory Energetics and Aerobic Capacity of the Gila Monster (Heloderma suspectum)
}

\author{
Henry B. John-Alder, Charles H. Lowe, and Albert F. Bennett \\ Department of Developmental and Cell Biology, University of California, Irvine, California 92717, USA
}

Accepted November 22, 1982

Summary. The thermal dependencies of sustainable locomotion and aerobic energetics were determined in the Gila monster, a lizard of relatively low thermal preference. Maximal aerobic speed (MAS) is $0.70 \mathrm{~km} / \mathrm{h}$ at $25^{\circ} \mathrm{C}$ and $1.03 \mathrm{~km} / \mathrm{h}$ at $35^{\circ} \mathrm{C}\left(\mathrm{Q}_{10}=1.5\right)$. Endurance declines as speed is increased above MAS, and Gila monsters are unusual in being unable to engage in brief periods of high-speed burst locomotion. The rate of $\mathrm{O}_{2}$ consumption $\left(\dot{V}_{\mathrm{O}_{2}}\right)$ during locomotion has the same thermal dependence as that of MAS. Maximal $\dot{V}_{\mathrm{O}_{2}}$ 's are $0.594 \mathrm{ml} \mathrm{O}_{2} /(\mathrm{g} \cdot \mathrm{h})$ at $25^{\circ} \mathrm{C}$ and $0.896 \mathrm{ml} \mathrm{O}_{2} /(\mathrm{g} \cdot \mathrm{h})$ at $35^{\circ} \mathrm{C}\left(\mathrm{Q}_{10}=1.5\right)$. The masscorrected $V_{\mathrm{O}_{2}}$ max of the Gila monsters is highest among lizards at $25^{\circ} \mathrm{C}$ and is relatively high, consistent with other platynotans, among lizards at $35^{\circ} \mathrm{C}$. Net cost of locomotion is temperature independent and is relatively low among lizards. Low net cost of locomotion together with high $\dot{V}_{\mathrm{O}_{2}} \max$ 's lead to Gila monsters having high MÂS's at both $25^{\circ} \mathrm{C}$ and $35^{\circ} \mathrm{C}$. Gila monsters thus appear to be well adapted for aerobic, sustainable activity. The total cost of locomotion shows a positive thermal dependence. However, the minimum cost of transport, attained at the highest sustainable speed, is temperature independent. Locomotion at MAS becomes faster with increasing body temperature with no obligatory increase in total cost of locomotion.

\section{Introduction}

The Gila monster (Heloderma suspectum) is one of two extant venomous species of lizards. This

Abbreviations: $P B T$ preferred body temperature; $\dot{V}_{\mathrm{O}_{2}}$ max maximal rate of $\mathrm{O}_{2}$ consumption; $\dot{V}_{\mathrm{O}_{2}}$ rest resting rate of $\mathrm{O}_{2}$ consumption; $M A S$ maximum aerobic speed; $R$ respiratory exchange ratio animal has a preferred body temperature (PBT) of $28-29^{\circ} \mathrm{C}$, and body temperatures in active lizards range from 24.2 to $33.7^{\circ} \mathrm{C}$ (Bogert and Martin del Campo 1956). The critical thermal maximum of this species is $41-43{ }^{\circ} \mathrm{C}$. All these temperatures are relatively low in comparison with other lizards (Brattstrom 1965). Seasonal and daily patterns of activity in Gila monsters reflect their thermal biology. Gila monsters in central Arizona are active from mid-March until early November, the exact dates of Spring emergence and Fall immergence being influenced by environmental temperature (Lardner 1969). Daily activity in early Spring and Fall is predominantly diurnal and is punctuated by periods of basking; late Spring and Summer activity is crepuscular (Lardner 1969). Activity periods of Gila monsters are thus restricted to thermally moderate periods.

Gila monsters have been described as "clumsy and slow-moving" (see Bogert and Martin del Campo 1956), and they are easily overtaken when pursued. According to the observations of Tucker (1967) relating behavior to aerobic scope, the behavior of Gila monsters would suggest that this species has very limited scope for activity. Behavioral capacities in Gila monsters may be restricted by the relatively low thermal preference of this species. Sustainable behavior in other lizards is markedly temperature dependent (Moberly 1968; John-Alder and Bennett 1981), with $\mathrm{Q}_{10}$ 's similar to those of underlying processes involved in the aerobic generation of energy for activity. However, the prey selection of Gila monsters would seem to require a wide-ranging foraging strategy for which aerobic energetic support would be essential, and one might expect Gila monsters to be adapted for activity at low body temperatures. High speed locomotion in lizards is supported largely by anaerobic metabolism, and even the highest aerobic 
locomotory speeds attainable by lizards are quite slow (see Bennett 1983). Therefore, a prediction of low aerobic capacity based on the absence of rapid locomotion would be ill-founded and misleading. The observations on locomotory behavior of Gila monsters may be related more closely to a defensive strategy that has evolved in association with the use of venom rather than to energetic capacities for sustainable activity.

The thermal biology of and behavioral observations on Gila monsters raise several questions regarding behavioral and physiological limits. What are the limits of sustainable and nonsustainable locomotion in Gila monsters? What is the aerobic capacity of this lizard and how does this limit behavior? What are the thermal dependencies of behavioral and physiological capacities? These questions are of particular interest in the context of the natural history of Gila monsters and are of general interest with regard to physiological correlates of behavior and thermal preferenda of lizards. This report presents the results of experiments designed to address these questions. We have measured $\mathrm{O}_{2}$ consumption $\left(\dot{V}_{\mathrm{O}_{2}}\right)$ and endurance capacity during regulated treadmill activity at two body temperatures in Gila monsters.

\section{Materials and Methods}

\section{Animal Collection and Maintenance}

Animals were captured near Tucson, Arizona (AZ Game and Fish Dept. Permit \#163 to C.H.L.) and housed at the University of Arizona for not more than three months prior to the experiments. Eleven lizards (mean body mass $\pm \mathrm{SE}=463.9 \pm 37.2 \mathrm{~g}$ ) were transported to the laboratory at the University of California, Irvine where measurements of $\dot{V}_{\mathrm{O}_{2}}, \mathrm{CO}_{2}$ production $\left(\dot{V}_{\mathrm{CO}_{2}}\right)$, and endurance at $25^{\circ} \mathrm{C}$ and $35^{\circ} \mathrm{C}$ were made in July and August, 1981. Animals were held on a 12:12 h day: night light cycle during separate experimental periods of 2-3 weeks. Night temperatures were $24^{\circ} \mathrm{C}$ or $32.5^{\circ} \mathrm{C}$, depending on the subsequent day's experiment, and were not scheduled systematically. Final adjustments of body temperature were made prior to measurements. Animals were held in individual cages with no food and unrestricted access to water during the experimental periods.

\section{Experimental Apparatus}

When measurements were to be made, an animal was removed from its cage and fit with a light-weight, transparent acetate mask, closed except for the head opening and an excurrent air line of Tygon tubing (OD 3/16"). A flexible thermistor was inserted $7 \mathrm{~cm}$ through the cloacal vent, and body temperature was monitored continuously with a tele-thermometer (YSI 46 TUC). Body temperature was regulated with a radiant heater and a small blower for convection. Average experimental body temperatures were $25.4 \pm 0.07^{\circ} \mathrm{C}$ (mean $\pm \mathrm{SE}$ ) and $35.1 \pm 0.03^{\circ} \mathrm{C}$.

Measurements of $\dot{V}_{\mathrm{O}_{2}}, \dot{V}_{\mathrm{CO}_{2}}$, and endurance were made on animals walking on a motor-driven treadmill. The tread belt was made of rubber-impregnated cloth with a top length. of $170 \mathrm{~cm}$ and width of $40 \mathrm{~cm}$. The treadmill was powered by a DC motor and had a speed range of $0.1-3.2 \mathrm{~km} / \mathrm{h}$. The gas analysis system was modified from John-Alder and Bennett (1981). Air was drawn at a controlled rate of approximately $1 \mathrm{l} / \mathrm{min}$ sequentially through the mask, a column of indicating Drierite for absorption of $\mathrm{H}_{2} \mathrm{O}$ vapor, a Brooks mass flow controller (model 5841), a Brooks rotameter, and an airtight diaphragm pump (Markson 6363). Air was vented through the barrel of a $50 \mathrm{ml}$ syringe and sampled continuously at $200 \mathrm{ml} /$ min through a column of indicating Drierite, an Applied Electrochemistry model S-3A O analyzer, a Beckman model LB-2 infrared $\mathrm{CO}_{2}$ analyzer, and a diaphragm pump venting into the room. Records of the concentrations of $\mathrm{O}_{2}$ and $\mathrm{CO}_{2}$ in the sample of dried, excurrent air were made on a Varian dualpen recorder (model 9176). Recordings were analyzed as described by John-Alder and Bennett (1981). The rate of $\mathrm{O}_{2}$ consumption was calculated with Eq. 3 b in Withers (1977), and $\dot{V}_{\mathrm{CO}_{2}}$ was calculated with Eq. 2 in Gleeson (1979).

\section{Experimental Protocol}

Resting rates of $\mathrm{O}_{2}$ consumption ( $\dot{V}_{\mathrm{O}_{2}}$ rest) were obtained on animals at $25^{\circ} \mathrm{C}$. A lizard was fit with the mask and thermistor as described. The animal was enclosed in a cotton bag and taped securely to the tread surface. After a rest period of $1 / 2 \mathrm{~h}$, the rate of $\mathrm{O}_{2}$ consumption was measured for at least $1 / 2 \mathrm{~h}$. During the period of measurement, the enclosed animal was observed constantly. Rates of $\mathrm{O}_{2}$ consumption were used for subsequent analysis only when they were obtained during periods of total inactivity and showed no systematic increasing or decreasing phases.

At the initiation of a walking trial, an enmasked animal was placed on the motionless tread belt, and the belt was accelerated quickly to the desired speed. The animal was stimulated to walk by tapping and squeezing the tail and hind limbs. A walking trial was discontinued when the initial few minutes of stimulation failed to elicit an even-paced locomotory response from the lizard. At $25^{\circ}$, walking at the initial speed was continued for $30 \mathrm{~min}$ or until the lizard had exhausted as indicated by $30 \mathrm{~s}$ of complete inactivity in the hind limbs. In this way, a measure of endurance was obtained simultancously with measurements of gas exchange. This procedure required that measurements be made at only one locomotory speed for each individual on a particular day at $25^{\circ} \mathrm{C}$. Maximal rates of $\mathrm{O}_{2}$ consumption $\left(\dot{V}_{\mathrm{O}_{2}}\right.$ max) were attained by lizards walking at non-sustainable speeds.

In a separate series of experiments at $25^{\circ} \mathrm{C}, \dot{V}_{\mathrm{O}_{2}} \max$ was elicited via a procedure of stepwise increments in speed. The tread speed was set initially at a low, sustainable speed, and an animal was stimulated to walk. When the record of $\mathrm{O}_{2}$ consumption had stabilized, tread speed was increased by $0.2 \mathrm{~km} / \mathrm{h}$, and the lizard was forced to walk at the new, higher speed until the record of $\mathrm{O}_{2}$ consumption had stabilized again. This procedure was repeated until the animal exhausted and could no longer sustain locomotion at the tread speed. Maximal $\dot{V}_{\mathrm{O}_{2}}$ was calculated from the record of highest $\mathrm{O}_{2}$ consumption.

At $35^{\circ} \mathrm{C}, \dot{V}_{\mathrm{O}_{2}}$ during locomotion was measured via a procedure of stepwise increments in speed similar to that used at $25^{\circ} \mathrm{C}$ to elicit $\dot{V}_{\mathrm{O}_{2}} \max$. An animal was forced to walk at the initial speed for a period of 20 to $30 \mathrm{~min}$ until the records of $\mathrm{O}_{2}$ and $\mathrm{CO}_{2}$ in excurrent air had remained stable for $10 \mathrm{~min}$. The tread speed was then increased by $0.2 \mathrm{~km} / \mathrm{h}$, and the lizard walked at the new, higher speed until stable levels of $\mathrm{O}_{2}$ and $\mathrm{CO}_{2}$ in excurrent air had been recorded for $10 \mathrm{~min}$. This procedure was repeated a third time, and records of $\mathrm{O}_{2}$ consumption and $\mathrm{CO}_{2}$ production at three speeds were obtained on an indi- 
vidual during a single trial. Individuals were subjected to the procedure on 2 days. Tread speeds on the second day were higher than on the first, and $\dot{V}_{\mathrm{O}_{2}}$ max was calculated from the record of highest $\mathrm{O}_{2}$ consumption attained at the highest speed. Individual walking trials were terminated by exhaustion of the lizard.

\section{Results}

\section{Performance at $25^{\circ} \mathrm{C}$}

Mass specific $\dot{V}_{\mathrm{O}_{2}}$ 's in lizards resting and walking on the treadmill at $25^{\circ} \mathrm{C}$ are reported in Fig. $1 \mathrm{~A}$. Resting $\dot{V}_{\mathrm{O}_{2}}$ averaged $0.057 \pm 0.010 \mathrm{ml} \mathrm{O}_{2} /(\mathrm{g} \cdot \mathrm{h})$ (mean $\pm \mathrm{SE} ; n=8$ ). Individual values for $\dot{V}_{\mathrm{O}_{2}}$ rest are reported on the ordinate and have been excluded from further analyses. Figure $1 \mathrm{~A}$ reports $\dot{V}_{\mathrm{O}_{2}}$ in lizards walking at one speed for $30 \mathrm{~min}$ or until exhaustion during endurance trials. There is a linear increase in $\dot{V}_{\mathrm{O}_{2}}$ with speed up to a maximal level $\left(\dot{V}_{\mathrm{O}_{2}} \max \right)$ that is not exceeded at higher speeds. The best-fitting pair of linear equations, determined by a procedure modified from Wilson (1974) and described in John-Alder and Bennett (1981), is used to describe $\dot{V}_{\mathrm{O}_{2}}$ as a function of speed. The following linear equations best describe the relationship between speed $(\mathrm{S})$ and $\dot{V}_{\mathrm{O}_{2}}$ at $25^{\circ} \mathrm{C}$ :

$$
\begin{array}{cl}
\dot{V}_{\mathrm{O}_{2}}=0.609(\mathrm{~S})+0.159 & 0.2 \leqq \mathrm{~S} \leqq 0.6 \mathrm{~km} / \mathrm{h} \\
& r=0.827, n=37, \\
& p<0.001 \\
\dot{V}_{\mathrm{O}_{2}}=0.018(\mathrm{~S})+0.565 & 0.8 \leqq \mathrm{~S} \leqq 1.5 \mathrm{~km} / \mathrm{h} \\
& r=0.060, n=16, \\
& p>0.75
\end{array}
$$

The slope of Eq. 2 is not significantly different from zero $(p>0.75)$ and is not plotted in Fig. $1 \mathrm{~A}$. Average $\dot{V}_{\mathrm{O}_{2}} \max \pm \mathrm{SE}$ attained by lizards walking to exhaustion at non-sustainable speeds during endurance trials is $0.585 \pm 0.030 \mathrm{ml} \mathrm{O} /(\mathrm{g} \cdot \mathrm{h})$. This value is reported in Fig. $1 \mathrm{~A}$ as a horizontal line with an error bar at its midpoint. The plot of Eq. 1 has been extrapolated to the y-intercept and to its point of intersection with the mean $\dot{V}_{\mathrm{O}_{2}} \max$. This extrapolated point of intersection gives an estimate of maximum aerobic speed (MAS), the speed at which $\dot{V}_{\mathrm{O}_{2}} \max$ is attained, of $0.70 \mathrm{~km} / \mathrm{h}$.

Independent measurements of $\dot{V}_{\mathrm{O}_{2}} \max$ were obtained at $25^{\circ} \mathrm{C}$ via the procedure of stepwise increments in speed. Individual values are reported in Table 1 , and the average $\dot{V}_{\mathrm{O}_{2}}$ max obtained via this procedure is indicated by a bold arrow on the ordinate in Fig. $1 \mathrm{~A}$. Mean $\dot{V}_{\mathrm{O}_{2}} \max \pm \mathrm{SE}$ obtained by the method of stepwise increments in speed at $25^{\circ} \mathrm{C}$ is $0.594 \pm 0.035 \mathrm{ml} \mathrm{O}_{2} /(\mathrm{g} \cdot \mathrm{h})$, a value not significantly different from that obtained via

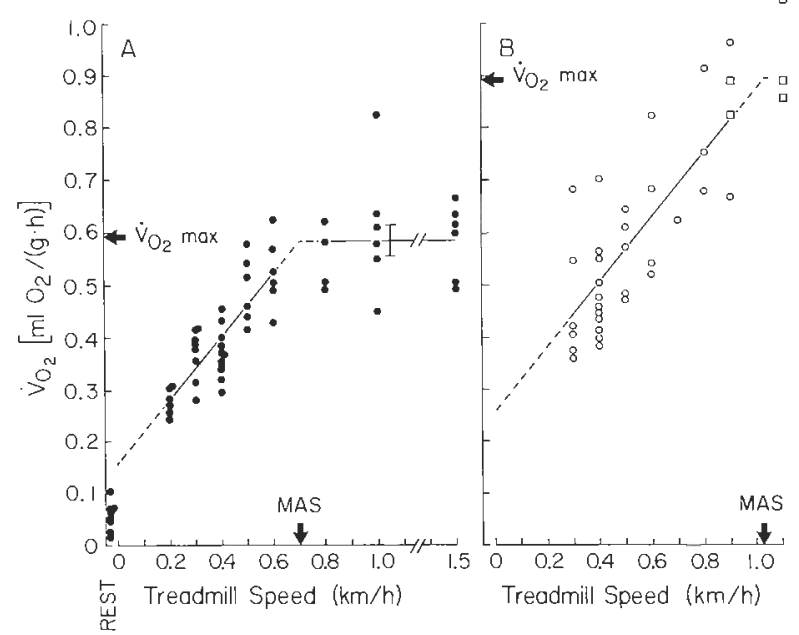

Fig. 1. Mass specific $\dot{V}_{\mathrm{O}_{2}}$ 's in lizards resting and walking on the treadmill at $25^{\circ} \mathrm{C}(\mathbf{A} ; \bullet)$ and walking at $35^{\circ} \mathrm{C}(\mathbf{B} ; \mathbf{O})$. Open squares in $\mathbf{B}$ indicate $\dot{V}_{\mathrm{O}_{2}} \max$ for individuals. Broken lines indicate extrapolations

Table 1. $\dot{V}_{\mathrm{O}_{2}}$ max attained during trials of stepwise increments in locomotory speed. Values in parentheses are average $\dot{V}_{\mathrm{O}_{2}}$ max's attained at non-sustainable speeds during endurance trials

\begin{tabular}{llll}
\hline $\begin{array}{l}\text { Animal } \\
\text { No. }\end{array}$ & $25{ }^{\circ} \mathrm{C}$ & $35{ }^{\circ} \mathrm{C}$ & $\mathrm{Q}_{10}$ \\
\hline 1 & & & \\
2 & $0.558(0.589)$ & 0.853 & 1.5 \\
3 & $0.581(0.618)$ & 0.884 & 1.5 \\
4 & $0.553(0.563)$ & 0.884 & 1.6 \\
5 & $0.563(0.485)$ & 0.819 & 1.5 \\
6 & $0.717(0.704)$ & 1.038 & 1.4 \\
\hline Mean \pm SE & $0.594 \pm 0.035$ & $0.896 \pm 0.042$ & $1.5 \pm 0.03$ \\
& $(0.585 \pm 0.033)$ & & \\
\hline
\end{tabular}

the procedure of walking to exhaustion at nonsustainable speeds during endurance trials $(p>$ $0.5)$. Thus, the two procedural variations used in this study give identical measurements of $\dot{V}_{\mathrm{O}_{2}} \max$ and may be used interchangeably.

Endurance at $25^{\circ} \mathrm{C}$ is reported as walking time as a function of speed in Fig. 2. Times of $30 \mathrm{~min}$ indicate trials that were terminated by the investigator, not by exhaustion of the lizard. There is a clear transition in walking times as speed increases above MAS. Endurance declines rapidly from 0.6 to $0.8 \mathrm{~km} / \mathrm{h}$ and declines further at $1.0 \mathrm{~km} / \mathrm{h}$. Endurance at $1.5 \mathrm{~km} / \mathrm{h}$ was only a few seconds for any individual and is indicated by one point for all individuals. There is clear correspondence between MAS and speeds that result in rapid exhaustion, and there is an extremely limited range of attainable speeds requiring supplemental anaerobic metabolic support. 


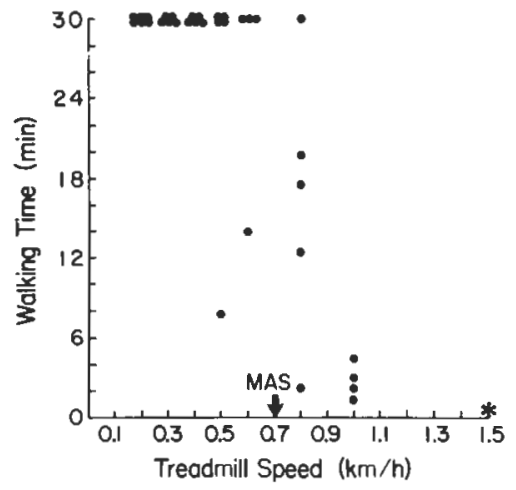

Fig. 2. Endurance of Gila monsters at $25^{\circ} \mathrm{C}$ reported as walking time versus speed. Times of 30 min represent trials that were terminated by the investigator. One point (*) at $1.5 \mathrm{~km} / \mathrm{h}$ represents five animals, none of which walked for more than a few seconds

Respiratory exchange ratios $\left(\mathrm{R}=\dot{V}_{\mathrm{CO}_{2}} / \dot{V}_{\mathrm{O}_{2}}\right)$ for lizards walking on the treadmill during endurance trials at $25^{\circ} \mathrm{C}$ are reported in Fig. $3 \mathrm{~A}$. There is a clear transition in mean $\mathrm{R}$ 's from approximately 1.0 at speeds below MAS to 1.2-1.4 at higher speeds. There is considerable variability in R's at any speed. $R$ is independent of speed below MAS $(p>0.25)$ and above MAS $(p>0.5)$. Average $\mathrm{R}$ is $1.00 \pm 0.03(n=37)$ below MAS and $1.30 \pm 0.06$ $(n=16)$ above MAS $(p<0.001)$. These observations indicate supplemental anaerobic metabolism (Gleeson and Bennett 1982) at speeds higher than MAS and further substantiate that lizards had exceeded their aerobic limits.

\section{Performance at $35^{\circ} \mathrm{C}$}

Figure $1 \mathrm{~B}$ presents $\dot{V}_{\mathrm{O}_{2}}$ as a function of speed in lizards walking on the treadmill at $35^{\circ} \mathrm{C}$. These data were collected via the procedure of stepwise increments in speed in which each in a series of speeds during one walking trial was sustained long enough to provide a stable record of $\dot{V}_{\mathrm{O}_{2}}$. Maximal $\dot{V}_{\mathrm{O}_{2}}$ 's were attained by individuals walking at their final speeds as described. Lizards were never forced to walk initially at non-sustainable speeds. Two lizards attained $\dot{V}_{\mathrm{o}_{2}} \max$ at $0.9 \mathrm{~km} / \mathrm{h}$, three at $1.1 \mathrm{~km} / \mathrm{h}$. Individual $\dot{V}_{\mathrm{O}_{2}}$ max's are presented in Table 1 and are indicated in Fig. $1 \mathrm{~B}$ by open squares. Mean $\dot{V}_{\mathrm{O}_{2}} \max \pm \mathrm{SE}$ is $0.892 \pm 0.046 \mathrm{ml} \mathrm{O}_{2} /(\mathrm{g} \cdot \mathrm{h})$ $(n=5)$. A single linear equation is used to describe $\dot{V}_{\mathrm{O}_{2}}$ as a function of speed below MAS:

$$
\begin{array}{cl}
\dot{V}_{\mathrm{O}_{2}}=0.617(\mathrm{~S})+0.258 & 0.3 \leqq \mathrm{~S} \leqq 0.9 \mathrm{k} / \mathrm{h} \\
& r=0.734, n=30, \\
& p<0.001
\end{array}
$$

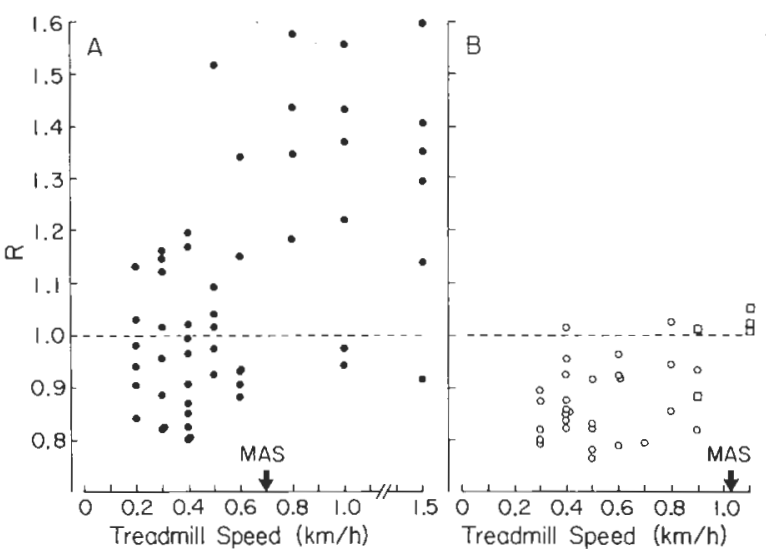

Fig. 3. Repiratory exchange ratios $(R)$ as a function of speed for individual lizards walking on the treadmill at $25^{\circ} \mathrm{C}(\mathbf{A}$; -) and at $35^{\circ} \mathrm{C}(\mathbf{B} ;$ o). Open squares in $\mathbf{B}$ indicate values calculated for animals consuming $\mathrm{O}_{2}$ at their maximal rates

The plot of Eq. 3 has been extrapolated to the yintercept and to its point of intersection with mean $\dot{V}_{\mathrm{O}_{2}} \max$. Estimated MAS is $1.03 \mathrm{~km} / \mathrm{h}$ at $35^{\circ} \mathrm{C}$.

Respiratory exchange ratios (R) for lizards walking on the treadmill at $35^{\circ} \mathrm{C}$ are reported in Fig. $3 \mathrm{~B}$. As at $25^{\circ} \mathrm{C}$, there is considerable variability in $R$ values at all speeds. $R$ is independent of speed below MAS $(p>0.05)$. Average $\mathrm{R}$ below MAS is $0.86 \pm 0.02(n=30)$ at $35^{\circ} \mathrm{C}$ and $1.00 \pm 0.03$ $(n=37)$ at $25^{\circ} \mathrm{C}(p<0.001)$. Values of $\mathrm{R}$ measured simultaneously with $\dot{V}_{\mathrm{O}} \max$ are reported in Fig. $3 \mathrm{~B}$ as open squares. The average $\mathrm{R}$ at $\dot{V}_{\mathrm{O}_{2}} \max$ is $1.00 \pm 0.06(n=6)$. This is significantly higher than $\mathrm{R}$ below MAS $(p<0.01)$.

\section{Discussion}

Heloderma suspectum is one of two extant species in the family Helodermatidae and is grouped together with lanthanotids and varanids in the superfamily Platynota (=Varanoidae) (Dowling and Duellman 1978). Helodermatids appeared early in the evolution of this group and are the only platynotans that occur in the New World. All varanids for which measurements are available have relatively high aerobic capacities (Gleeson 1981; Bennett 1982), and the lungs of varanids have a relatively large surface area for gas exchange. These observations suggest that this group is exceptional among lizards in aerobic metabolism during activity. If high aerobic capacities appeared early in the evolution of platynotans and were conserved in extant species, then one might expect helodermatids to have similarly high aerobic capacities. In this context, a comparison of aerobic capa- 
Table 2. $\dot{V}_{\mathrm{O}_{2}} \max ^{\text {corr }}$ for lizards at $25^{\circ} \mathrm{C}$ and $35^{\circ} \mathrm{C}^{\mathrm{a}}$

\begin{tabular}{|c|c|c|c|c|c|c|}
\hline \multirow[t]{2}{*}{ Species } & \multirow{2}{*}{$\begin{array}{l}\text { Mass } \\
\text { (g) }\end{array}$} & \multirow{2}{*}{$\begin{array}{l}\text { PBT } \\
{ }^{\circ} \mathrm{C}\end{array}$} & \multicolumn{2}{|c|}{$\dot{V}_{\mathrm{O}_{2}} \max ^{\mathrm{corr}}$} & \multirow[t]{2}{*}{$Q_{10}$} & \multirow[t]{2}{*}{ Reference } \\
\hline & & & $25^{\circ} \mathrm{C}$ & $35^{\circ} \mathrm{C}$ & & \\
\hline Amblyrhynchus cristatus & 489 & 35 & 2.34 & 4.20 & 2.2 & Bennett et al. 1975 \\
\hline Amphibolurus barbatus & 239 & 35.7 & 1.76 & 2.42 & 1.6 & Wilson 1974 \\
\hline Cnemidophorus tigris & 18 & 40 & - & 3.20 & - & Asplund 1970 \\
\hline Dipsosaurus dorsalis & 35.2 & 40 & - & 3.86 & 2.2 & Bennett and Dawson 1972 \\
\hline Dipsosaurus dorsalis & 50 & 40 & 2.12 & - & 2.2 & John-Alder and Bennett 1981 \\
\hline Egernia cunninghami & 258 & 32.5 & 1.66 & 2.27 & 1.6 & Wilson 1974 \\
\hline Gerrhonotus multicarinatus & 24 & & 0.85 & 2.42 & 2.8 & Hoffman 1973 \\
\hline Heloderma suspectum & 444.8 & 28.5 & 3.08 & 3.85 & 1.5 & present study \\
\hline Iguana iguana & 709 & 35 & - & 4.01 & 2.6 & Gleeson et al. 1980 \\
\hline Iguana iguana & 795 & 35 & 1.52 & - & 2.6 & Moberly 1968 a \\
\hline Physignathus lesueuri & 549 & 30.1 & 1.87 & 2.05 & 1.3 & Wilson 1974 \\
\hline Sauromalus hispidus & 574 & 37.1 & 1.50 & 2.44 & 2.0 & Bennett 1972 \\
\hline Sceloporus occidentalis & 133.1 & 35 & 1.80 & 3.30 & 2.0 & Bennett and Gleeson 1976 \\
\hline Tiliqua rugosa & 421 & 32.6 & 1.79 & 3.24 & 2.5 & Wilson 1974 \\
\hline Tupinambis nigropunctatus & 1,077 & 35 & - & 3.97 & - & Bennett, unpub. \\
\hline Varanus exanthematicus & 1,025 & 35 & - & 3.97 & - & Gleeson et al. 1980 \\
\hline Varanus gouldii & 674 & 37.1 & 2.32 & 3.63 & 1.9 & Bennett 1972 \\
\hline Varanus salvator & 505 & 35 & - & 3.97 & - & Gleeson 1981 \\
\hline Mean & & & $\begin{array}{l}1.98 \\
(n=12)\end{array}$ & $\begin{array}{l}3.46 \\
(n=16)\end{array}$ & & \\
\hline
\end{tabular}

a Mass exponent $=0.73$ at $25^{\circ} \mathrm{C}$ and 0.76 at $35^{\circ} \mathrm{C}$

cities between the Gila monster and other platynotans is of particular interest.

Maximal $\dot{V}_{\mathrm{O}_{2}}$ 's cannot be compared directly because of the nonlinear relationship between $\dot{V}_{\mathrm{O}_{2}}$ max and body mass (Bennett and Dawson 1976). We have summarized literature data in Table 2 , correcting $\dot{V}_{\mathrm{O}_{2}} \max$ at $35^{\circ} \mathrm{C}$ using mass ${ }^{0.76}$ according to the allometric equation presented by Bennett (1982). For Gila monsters at $35^{\circ} \mathrm{C}$, $\dot{V}_{\mathrm{O}_{2}} \max ^{\text {corr }}=3.85 \mathrm{ml} \mathrm{O}_{2} /\left(\mathrm{g}^{0.76} \cdot \mathrm{h}\right)$, a value that is not exceptional among lizards: the average of 16 corrected values at $35^{\circ} \mathrm{C}$ is $3.46 \mathrm{ml} \mathrm{O}_{2} /\left(\mathrm{g}^{0.76} \cdot \mathrm{h}\right)$. Platynotans (varanids and Heloderma) have significantly higher aerobic capacities than other lizards tabulated ( $p<0.01$, one-tailed $t$-test). However, other phylogenetic groupings of lizards do not have distinct levels of $\dot{V}_{\mathrm{O}_{2}} \max$. Phylogenetic affinity apparently has not been of overriding importance in establishing aerobic capacity among these groups. A similar comparison of aerobic capacities at $25^{\circ} \mathrm{C}$ can be made with mass ${ }^{0.73}$ to correct for size effects on $\dot{V}_{\mathrm{O}_{2}}$ max. For the Gila monster at $25^{\circ} \mathrm{C}, \dot{V}_{\mathrm{O}_{2}} \max ^{\mathrm{corr}}=3.08 \mathrm{ml} \mathrm{O}{ }_{2} /\left(\mathrm{g}^{0.73} \cdot \mathrm{h}\right)$, the highest value reported for any lizard at $25^{\circ} \mathrm{C}$ (Table 2 ). Again the platynotans have significantly higher $\dot{V}_{\mathrm{O}_{2}}$ max ${ }^{\text {corr }}$ 's $(p<0.01$, one-tailed $t$-test $)$.

The thermal dependencies of corrected $\dot{V}_{\mathrm{O}_{2}}$ max's at $25^{\circ} \mathrm{C}$ and $35^{\circ} \mathrm{C}$ range from $\mathrm{Q}_{10}=1.3$ to $\mathrm{Q}_{10}=2.8$ (Table 2). The average of tabulated $\mathrm{Q}_{10}$ 's is $1.93 \pm 0.15$ (mean $\pm \mathrm{SE}$ ). The $\mathrm{Q}_{10}$ for
$\dot{V}_{\mathrm{O}_{2}} \max$ in Heloderma suspectum (1.5) is low among the tabulated values. Thermal expansibility of $\dot{V}_{\mathrm{O}_{2}}$ max in this species is low, preventing major alteration in aerobic capacity with changing body temperature.

The rate of $\mathrm{O}_{2}$ consumption during locomotion in the Gila monster shows a positive thermal dependence from $25^{\circ} \mathrm{C}$ to $35^{\circ} \mathrm{C}$. By analysis of covariance, the slopes of $\dot{V}_{\mathrm{O}_{2}}$ on speed at $25^{\circ} \mathrm{C}$ (Eq. 1: 0.609) and at $35^{\circ} \mathrm{C}$ (Eq. 3: 0.617) are not significantly different $(p>0.5)$, and the y-intercept at $35^{\circ} \mathrm{C}$ is significantly higher than at $25^{\circ} \mathrm{C}(p<$ $0.001)$. Thus, the total energetic requirements of sustainable locomotion at identical speeds are greater at $35^{\circ} \mathrm{C}$ than at $25^{\circ} \mathrm{C}$. The dependence of $\dot{V}_{\mathrm{O}_{2}}$ on locomotory speed at $35^{\circ} \mathrm{C}$ is essentially a proportional expansion of the relationship at $25^{\circ} \mathrm{C}$. Thermal factorial increments for the y-intercept, $\dot{V}_{\mathrm{O}_{2}} \max$, and MAS are nearly identical, $\mathrm{Q}_{10}$ 's being approximately 1.5 . The rate of $\mathrm{O}_{2}$ consumption during locomotion in Dipsosaurus dorsalis shows a very similar pattern of thermal expansibility (John-Alder and Bennett 1981).

There is a very close similarity between MAS (Fig. $1 \mathrm{~A}$ ) and the maximal sustainable speed at $25^{\circ} \mathrm{C}$ (Fig. 2). In Dipsosaurus, MAS is very close to the maximal sustainable speed at both $25^{\circ} \mathrm{C}$ and $40{ }^{\circ} \mathrm{C}$ (John-Alder and Bennett 1981). Thus, MAS appears to be a good predictor of maximal sustainable speed. Maximum aerobic speed in the 
Gila monster at $35^{\circ} \mathrm{C}$ is $1.03 \mathrm{~km} / \mathrm{h}$; maximal sustainable speed would be expected to be about $1.0 \mathrm{~km} / \mathrm{h}$. While locomotion at any sustainable speed is more costly at $35^{\circ} \mathrm{C}$ than at $25^{\circ} \mathrm{C}$, the range of sustainable speeds is higher at the higher temperature.

The relationship between $\dot{V}_{\mathrm{O}_{2}}$ and speed is the most commonly used basis for evaluating energetic costs of sustainable locomotion. Such analyses are instructive in terms of the physiology of locomotion and the biology of the animal under natural conditions. The total energetic cost of locomotion (C) , calculated as $\dot{V}_{\mathrm{O}_{2}} /$ speed at or below MAS, is a useful formulation for understanding the total energy budget of an animal under natural conditions. As locomotory speed increases, the time required to traverse a unit distance decreases. Thus, the duration of maintenance and postural costs decreases, and the contribution of these costs to $C_{t}$ declines with speed according to an hyperbolic function (Fig. 4). Within the limits of aerobic locomotion, high speeds are less costly than low speeds in terms of transporting mass over distance, and the minimum cost of transport $\left(\mathrm{C}_{\mathrm{t}} \mathrm{min}\right)$ is attained at MAS. Equations 1 and 3 have been used to generate the plots of $\mathrm{C}_{1}$ at $25^{\circ} \mathrm{C}$ and $35^{\circ} \mathrm{C}$ in Fig. 4 . Total cost of locomotion at any sustainable speed is greater at $35^{\circ} \mathrm{C}$ than at $25^{\circ} \mathrm{C}$. For example, $\mathrm{C}_{1}$ at $0.4 \mathrm{~km} / \mathrm{h}$ is $1.26 \mathrm{ml} \mathrm{O}_{2} /(\mathrm{g} \cdot \mathrm{km})$ at $35^{\circ} \mathrm{C}$ versus $1.01 \mathrm{ml} \mathrm{O} /(\mathrm{g} \cdot \mathrm{km})$ at $25^{\circ} \mathrm{C}$. The range of aerobic locomotory speeds shows the same positive thermal dependence as $\dot{V}_{\mathrm{O}_{2}}$ during locomotion, and MAS is $1.08 \mathrm{~km} / \mathrm{h}$ at $35^{\circ} \mathrm{C}$ versus $0.70 \mathrm{~km} / \mathrm{h}$ at $25^{\circ} \mathrm{C}$. Consequently, $\mathrm{C}_{\mathrm{t}} \mathrm{min}$ is temperature independent: $0.87 \mathrm{ml} \mathrm{O} /(\mathrm{g} \cdot \mathrm{km})$ at $35^{\circ} \mathrm{C}$ versus $0.84 \mathrm{ml} \mathrm{O}_{2} /(\mathrm{g} \cdot \mathrm{km})$ at $25^{\circ} \mathrm{C}$. Thermal independence of $\mathrm{C}_{\mathrm{t}}$ min has been reported in Dipsosaurus dorsalis (John-Alder and Bennett 1981), the only other species for which this analysis can be made. These animals expand their ranges of sustainable locomotory speeds at higher body temperatures and are capable of higher speeds with no obligatory increment in locomotory costs.

The rate of $\mathrm{O}_{2}$ consumption during locomotion can be factored into maintenance costs, postural costs, and costs of locomotory activity per se. Maintenance and postural costs are isolated from locomotory costs by subtracting the $y$-intercept from $\dot{V}_{\mathrm{O}_{2}}$ during locomotion at sustainable speeds. The net cost of locomotion then is given by $\left(\dot{V}_{\mathrm{O}_{2}}\right.$ - y-intercept)/speed, the slope of $\dot{V}_{\mathrm{O}_{2}}$ on speed (Schmidt-Nielsen 1972). The net cost of locomotion in $H$. suspectum is $0.609 \mathrm{ml} \mathrm{O} /(\mathrm{g} \cdot \mathrm{km})$ at $25^{\circ} \mathrm{C}$ (Eq. 1) and $0.617 \mathrm{ml} \mathrm{O} /(\mathrm{g} \cdot \mathrm{km})$ at $35^{\circ} \mathrm{C}$ (Eq. 2), values that are not significantly different

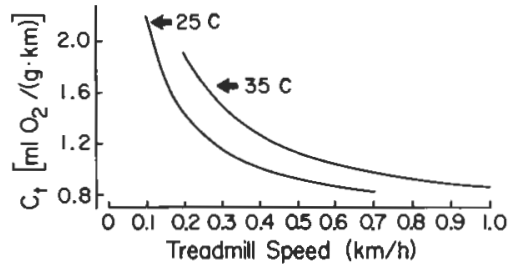

Fig. 4. Total cost of locomotion $\left(\mathrm{C}_{\mathrm{t}}\right)$ for animals walking at $25^{\circ} \mathrm{C}$ and at $35^{\circ} \mathrm{C}$. Equations 1 and 3 were used to generate these lines. See text for details

$(p>0.50)$. Net cost of locomotion for the Gila monster is $76 \%$ of the value for a lizard of $460 \mathrm{~g}$ body mass predicted by the allometric relationship between net cost of locomotion and body mass formulated by Gleeson (1979), and it is outside the $95 \%$ confidence interval of the regression of $\log$ net cost of locomotion on log body mass. Thus, the Gila monster has a relatively low net cost of locomotion in comparison to other lizards.

Gila monsters are unusual among lizards in being unable to engage in short periods of strenuous burst activity. Endurance declines rapidly at speeds above MAS and is only a few seconds at $1.5 \mathrm{~km} / \mathrm{h}$ (Fig. 2). It is more typical of lizards to engage in brief periods of burst locomotion that enable them to run at speeds an order of magnitude greater than MAS (Bennett 1980; Marsh and Bennett, pers. com.). Bogert and Martin del Campo (1956) reported a maximum locomotory speed of $1.27 \mathrm{~km} / \mathrm{h}$ in Gila monsters $\left(T_{\mathrm{b}}\right.$ : $22.8-26.7^{\circ} \mathrm{C}$ ) escaping from a hot substrate on which they had been placed, a procedure that would evoke sprint running in many lizards. These observations together with the endurance data presented here corroborate the widespread anecdotal reputation of the Gila monster as a sluggish lizard. Gila monsters would rarely be presented with situations in which rapid locomotion would be advantageous. Primary prey items include eggs of ground-nesting birds and juvenile mammals retrieved from burrows (Bogert and Martin del Campo 1956). Clearly, rapid pursuit would not be involved in subduing either of these prey types. In fact, captive Gila monsters are apparently unable to overtake untethered adult rodents. Few animals prey on Gila monsters, and in staged encounters, these lizards are usually successful in repelling adversaries through a combination of hissing sounds and an open-mouthed defensive posture. At close range, Gila monsters are able to respond to persistent threats with very rapid biting maneuvers. This behavior in a lizard with high aerobic capacity is an exception to the pattern observed by Tucker (1967) in which lizards with rela- 
tively high aerobic scopes tended to flee rapidly while those with more limited scopes tended to rely on static defense behavior. Flight behavior is characterized by rapid locomotion of short duration, activity that is supported largely by anaerobiosis. The observations of Tucker (1967) thus may have been fortuitous, leading to a misleading association between aerobic scope and an anaerobically supported behavior. The adaptive significance of the relatively high limits on aerobic activity in the Gila monster is to be seen in other aspects of the behavior of this species.

The prey selection of Gila monsters would require a wide-ranging foraging strategy, and this lizard appears to be well-adapted for this in terms of locomotory energetics. Net cost of locomotion is relatively low in comparison with other lizards, and $\dot{V}_{\mathrm{O}_{2}} \max$ is relatively high. Thus incremental changes in $\dot{V}_{\mathrm{O}_{2}}$ with increasing speed are relatively low, and $\dot{V}_{\mathrm{O}_{2}} \max$ is attained at a relatively high MAS. In comparison to other lizards, the Gila monster would be expected to attain higher speeds at equivalent rates of $\mathrm{O}_{2}$ consumption and thus would be able to traverse greater distances with no additional cost in terms of time or energy. This pattern of locomotory energetics would seem to be clearly advantageous for an animal foraging for widely distributed prey, such as bird eggs and juvenile mammals. Gila monsters are exceptional in their endurance capacity during sustainable activity; "slow and clumsy" appears to be an imprecise description of the locomotory behavior of this species. The physiological and morphological bases of the variability apparent in locomotory costs of lizards are unclear. Fedak and Seeherman (1979) have observed that cursorial, fast, or graceful mammals tend to have relatively low net costs of locomotion. Similar adaptations may be present in lizards; however, more data will be required for a thorough analysis of locomotory energetic adaptations in this group.

Seasonal and daily activity periods in Gila monsters are limited to some extent by environmental temperatures (Lardner 1969), and the minimum activity temperature is reported to be $24.2{ }^{\circ} \mathrm{C}$ (Bogert and Martin del Campo 1956). Preferred body temperature in active Gila monsters is $28-29^{\circ} \mathrm{C}$, and the maximum voluntarily tolerated body temperature is $32.7^{\circ} \mathrm{C}$. The data presented here indicate that Gila monsters would be able to forage over greater distances at $35^{\circ} \mathrm{C}$ than at $25^{\circ} \mathrm{C}$ with no obligatory increment in locomotory costs. Presumably, the importance of avoiding high body temperatures for unidentified behavioral and physiological reasons outweighs the thermal improvement in performance. However, thermal improvements in performance may have been one of the selective pressures associated with the evolution of PBT and Winter inactivity in Gila monsters. This species is particularly poorly adapted for brief bursts of anaerobically supported activity. Low limits on aerobic activity may create a prohibitively high ratio of costs to benefits during activity at low body temperatures and thus exclude this from the behavioral repertoire of the Gila monster.

Acknowledgements. We thank Drs. R.B. Huey, R.L. Marsh, and K.A. Nagy for helpful comments during the preparation of this manuscript. Ms. K.L. John-Alder skillfully prepared the figures. Supported by NSF Grant PCM 81-02331 to AFB and an award from the UC Chancellor's Patent Fund to HBJ-A.

\section{References}

Asplund KK (1970) Metabolic scope and body temperatures of whiptail lizards (Cnemidophorus). Herpetologica $26: 403411$

Bennett AF (1972) The effect of activity on oxygen consumption, oxygen debt, and heart rate in the lizards Varanus gouldii and Sauromalus hispidus. J Comp Physiol 79:259-280

Bennett AF (1980) The thermal dependence of lizard behaviour. Anim Behav 28: 752-762

Bennett AF (1982) The energetics of reptilian activity. In: Gans C, Pough FH (eds) Biology of the Reptilia, vol 13. Academic Press, New York, pp 155-199

Bennett AF, Dawson WR (1972) Aerobic and anaerobic metabolism during activity in the lizard Dipsosaurus dorsalis. J Comp Physiol $81: 289-299$

Bennett AF, Dawson WR (1976) Metabolism. In: Gans C, Pough FH (eds) Biology of the Reptilia, vol 5. Academic Press, New York, pp 127-223

Bennett AF, Dawson WR, Bartholomew GA (1975) Effects of activity and temperature on aerobic and anaerobic metabolism in the Galapagos marine iguana. J Comp Physiol 100:317-329

Bennett AF, Gleeson TT (1976) Activity metabolism in the lizard Sceloporus occidentalis. Physiol Zool 49:65-76

Bogert CM, Martin del Campo R (1956) The Gila monster and its allies. Bull Am Mus Nat Hist 109: Article 1

Brattstrom BH (1965) Body temperatures of reptiles. Am Mid Nat 73:376-422

Dowling HG, Duellman WE (1978) Systematic herpetology: A synopsis of families and higher categories. HISS Publications, New York (Publications in Herpetology No 7)

Fedak MA, Seeherman HJ (1979) Reappraisal of energetics of locomotion shows identical cost in bipeds and quadrupeds including ostrich and horse. Nature 282:713-716

Gleeson TT (1979) Foraging and transport costs in the Galapagos marine iguana, Amblyrhynchus cristalus. Physiol Zool $52: 549-557$

Gleeson TT (1981) Preferred body temperature, aerobic scope, and activity capacity in the monitor lizard, Varanus salvator. Physiol Zool 54:423 429

Gleeson TT, Bennett AF (1982) Acid-base imbalance in lizards during activity and recovery. J Exp Biol 98:439 453

Gleeson TT, Mitchell GS, Bennett AF (1980) Cardiovascular responses to graded activity in the lizards Varanus and Iguana. Am J Physiol 239: R 174-R 179 
Hoffman M (1973) Locomotor activity, body temperature, and metabolic scope in the southern alligator lizard Gerrhonotus multicarinatus webbi (Anguidae). M.A. Thesis, Calif State Univ, Fullerton

John-Alder HB, Bennett AF (1981) Thermal dependence of endurance and locomotory energetics in a lizard. Am J Physiol 241 : R 342-R 349

Lardner PJ (1969) Diurnal and seasonal locomotory activity in the Gila monster, Heloderma suspectum Cope. PhD Dissertation, Univ Ariz Tucson

Moberly WR (1968a) The metabolic responses of the common iguana, Iguana iguana, to activity under restraint. Comp Biochem Physiol 27:1-20

Moberly WR (1968b) The metabolic responses of the common iguana, Iguana iguana, to walking and diving. Comp Biochem Physiol 27:21-32

Schmidt-Niclsen K (1972) Locomotion: energy cost of swimming, flying, and running. Science 177:222-228

Tucker VA (1967) The role of the cardiovascular system in oxygen transport and thermoregulation in lizards. In: Milstead WW (ed) Lizard ecology: A Symposium. Univ Missouri Press, Columbia, pp 258-269

Wilson KJ (1974) The relationship of oxygen supply for activity to body temperature in four species of lizards. Copeia 1974:920-934

Withers PC (1977) Measurement of $\dot{V}_{\mathrm{O}_{2}}, \dot{V}_{\mathrm{CO}_{2}}$, and evaporative water loss with a flow-through mask. J Appl Physiol: Respirat Environ Exercise Physiol 42:120-123 